\title{
$2-2015$
}

\section{Representing taxonomic, phylogenetic and functional diversity: new challenges for Mediterranean marine-protected areas}

Francois Guilhaumon

Camille Albouy

et al

Christine N. Meynard

Virginia Institute of Marine Science

et al

Follow this and additional works at: https://scholarworks.wm.edu/vimsarticles

Part of the Marine Biology Commons, and the Natural Resources and Conservation Commons

\section{Recommended Citation}

Guilhaumon, Francois; Albouy, Camille; et al; Meynard, Christine N.; and et al, Representing taxonomic, phylogenetic and functional diversity: new challenges for Mediterranean marine-protected areas (2015). Diversity and Distributions, 21(2), 175-187.

DOI: $10.1111 /$ ddi.12280

This Article is brought to you for free and open access by the Virginia Institute of Marine Science at W\&M ScholarWorks. It has been accepted for inclusion in VIMS Articles by an authorized administrator of W\&M ScholarWorks. For more information, please contact scholarworks@wm.edu. 


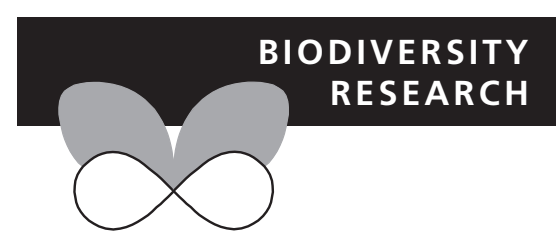

Representing taxonomic, phylogenetic and functional diversity: new challenges for Mediterranean marine-protected areas

François Guilhaumon ${ }^{1,2 \dagger}$, Camille Albouy ${ }^{2,3 \dagger}$, Joachim Claudet ${ }^{4,5}$, Laure Velez ${ }^{2}$, Frida Ben Rais Lasram ${ }^{6}$, Jean-Antoine Tomasini ${ }^{2}$, Emmanuel J. P. Douzery ${ }^{7}$, Christine N. Meynard ${ }^{7,8,9}$, Nicolas Mouquet ${ }^{7}$, Marc Troussellier ${ }^{2}$, Miguel B. Araújo ${ }^{1,10,11,12}$ and David Mouillot ${ }^{2,13}$

${ }^{1}$ 'Rui Nabeiro' Biodiversity Chair, CIBIO, University of Évora, Casa Cordovil, $2^{\circ}$ Andar, Rua Dr. Joaquim Henrique da Fonseca, 7000890 c, Portugal, ${ }^{2} I R D$, UMR 5119, IRD-CNRS -IFREMER-UM2-UM1 ECOSYM, Université Montpellier 2, cc 093, Place E. Bataillon, 34095 Montpellier Cedex 05, France, ${ }^{3}$ Département de Biologie, Chimie et Géographie, Université du Québec à Rimouski, 300 Allée des Ursulines, Rimouski, QC, Canada G5L 3A1, ${ }^{4}$ National Center for Scientific Research, USR 3278, CNRS-EPHE CRIOBE, University of Perpignan, 66860 Perpignan Cedex, France, ${ }^{5}$ Laboratoire d'Excellence 'CORAIL',

${ }^{6}$ Laboratoire Écosystèmes et Ressources Aquatiques UR03AGRO1, Institut National Agronomique de Tunisie, 43 Avenue Charles Nicolle, 1082 Tunis, Tunisia, ${ }^{7}$ Institut des Sciences de l'Evolution, UMR 5554, CNRS, UM2, cc 065, Place E. Bataillon, 34095 Montpellier Cedex 05, France, ${ }^{8}$ INRA, UMR CBGP (INRA/IRD/Cirad/Montpellier SupAgro), Campus International de Baillarguet, CS 30016, FR-34988 Montferrier-sur-Lez cedex, France, ${ }^{9}$ Virginia Institute of Marine Science, College of William \& Mary, PO Box 1346, Gloucester Point, VA 23062, USA,

${ }^{10}$ Departamento de Biogeografía y Cambio Global, Museo Nacional de Ciencias Naturales, CSIC, C/José Gutiérrez Abascal, 2, 28006 Madrid, Spain, ${ }^{11}$ Center for Macroecology, Evolution and Climate, University of Copenhagen, Universitetsparken 15, 2100 Copenhagen, Denmark, ${ }^{12}$ Division of Ecology and Evolution, Imperial College London, Silwood Park, Buckhurst Road, Ascot, Berkshire SL5 7PY, UK, ${ }^{13}$ ARC Centre of Excellence for Coral Reef Studies, James Cook University,

Townsville, Qld 4811, Australia

${ }^{\star}$ Correspondence: François Guilhaumon. E-mail: francois.guilhaumon@ird.fr

${ }^{\dagger}$ These authors contributed equally to this work.

\section{ABSTRACT}

Aim To assess gaps in the representation of taxonomic, phylogenetic and functional diversity among coastal fishes in Mediterranean marine-protected areas (MPAs).

\section{Location Mediterranean Sea.}

Methods We first assessed gaps in the taxonomic representation of the 340 coastal fish species in Mediterranean MPAs, with representation targets (the species range proportion to be covered by MPAs) set to be inversely proportional to species' range sizes. We then asked whether MPAs favoured representation of phylogenetically and functionally more distinct species or whether there was a tendency to favour less distinctive ones. We finally evaluated the overall conservation effectiveness of the MPAs using a metric that integrates species' phylogenetic and functional relationships and targets achievement. The effectiveness of the MPA system at protecting biodiversity was assessed by comparison of its achievements against a null model obtained by siting current MPAs at random over the study area.

Results Among the coastal fish species analysed, 16 species were not covered by any MPA. All the remaining species only partially achieved the pre-defined representation target. The current MPA system missed fewer species than expected from siting MPAs at random. However, c. 70\% of the species did not achieve better protection in the current MPAs than expected from siting MPAs at random. Functional and evolutionary distinctiveness were weakly correlated with target achievement. The observed coverage of taxonomic, phylogenetic and functional diversity was not different or lower than expected from siting MPAs at random.

Main conclusions The Mediterranean MPA system falls short in meeting conservation targets for coastal fish taxonomic diversity, phylogenetic diversity and functional diversity. Mediterranean MPAs do not encompass more biodiversity than expected by chance. This study reveals multiple ongoing challenges and calls for regional collaboration for the extension of the Mediterranean system of MPAs to meet international commitments and reduce the ongoing loss of marine biodiversity.

\section{Keywords}

Functional diversity, gap analysis, marine-protected area, Mediterranean fishes, phylogenetic diversity, reserves, taxonomic diversity. 


\section{INTRODUCTION}

The Mediterranean Sea is a remnant of the Tethys Ocean and has shown exceptional levels of marine biodiversity since the late Middle Eocene (42-39 Ma; Renema et al., 2008). Today, despite representing only $0.32 \%$ of the global ocean volume, the Mediterranean Sea contains c. 7\% of the world's marine biodiversity (c. 17000 species spanning all levels of biological organization; Coll et al., 2010) with approximately onequarter being endemic to the region (Bianchi \& Morri, 2000). Fish assemblages, in particular, represent a key component of aquatic ecosystems (Holmlund \& Hammer, 1999). Fish provide fundamental services essential for ecosystem function and resilience such as, among others, the regulation of food web dynamics (Myers et al., 2007), nutrient balances (Vanni 2002) and carbon fluxes (Schindler et al., 1997). Furthermore fish exploitation has been central to the development of Mediterranean civilizations across history (Coll et al., 2010).

Most of the Mediterranean marine biodiversity is located on the continental shelf (Ben Rais Lasram et al., 2009; Coll et al., 2012), an area that has been historically impacted by numerous anthropogenic threats (Myers et al., 2000; Claudet \& Fraschetti, 2010; Costello et al., 2010). Climate change and overfishing, in particular, are considered as severely affecting coastal fish populations (Guidetti et al., 2002; Coll et al., 2010, 2012; Albouy et al., 2012). To counteract these threats, marine-protected areas (MPAs) have been shown to promote sustainable fisheries (Roberts et al., 2005; Alós \& Arlinghaus, 2013) and the resilience of marine organisms to climatic impacts (Micheli et al., 2012). Overall, more than 100 MPAs have been established in the Mediterranean Sea since the 1960s (Abdulla et al., 2009). However, the most recent investigations suggest that coastal Mediterranean MPAs do not deliver in several important respects. First, they do not meet international conservation goals (e.g. Convention on Biological Diversity, CBD; COP10, Decision X/2, Strategic goal C, target 11 of protecting at least $10 \%$ of coastal and marine areas by 2020) with less than $2.5 \%$ of the surface area of the Mediterranean continental shelf covered (excluding the Pelagos Sanctuary, dedicated exclusively to the protection of marine mammals; Notarbartolo-Di-Sciara et al., 2008). Second, MPAs have been established based on national or local initiatives and lack cross-regional consistency (Guidetti et al., 2008; Claudet et al., 2011). Finally, there is evidence for a mismatch between current MPAs and areas that contain a large fraction of the regional evolutionary history (i.e. phylogenetic diversity hotspots) or areas with high levels of biological trait diversity (i.e. functional diversity hotspots; Mouillot et al., 2011). Yet, phylogenetic diversity represents the building blocks of the diversity of life (Mace et al., 2003; Forest et al., 2007), and functional diversity is essential to the functioning of ecosystems and the provision of services upon which human welfare depends (Hooper et al., 2005; Cadotte et al., 2009; Clemente et al., 2010; Faith et al., 2010). Hence, the overall representativeness of the current Mediterranean MPA system, that is whether it captures sufficient levels of all biodiversity components, is open to question.

Beyond taxonomic diversity, several studies have stressed the need to account for the different components of biodiversity when establishing conservation area networks (Vane Wright et al., 1991; Humphries et al., 1995; Cadotte \& Davies, 2010; Pio et al., 2011; Tucker et al., 2012). This is because species are not all equivalent, with some clades carrying more evolutionary history, or performing more singular functions in the ecosystem, than others (Vane Wright et al., 1991; Isaac et al., 2007; Mouillot et al., 2008; Cadotte \& Davies, 2010). Therefore, quantitatively measuring the coverage of different biodiversity features by protected area systems is the essential first step towards effective conservation (Margules \& Pressey, 2000; Scott et al., 2001; Gaston et al., 2002). To this aim, 'gap analysis' is a well-established method that overlays biodiversity maps with protected area maps to evaluate the effectiveness with which protected areas cover selected biodiversity features (Scott et al., 1993; Jennings, 2000; Rodrigues et al., 2004a,b; Maiorano et al., 2006; Araújo et al., 2007). Here, we develop a gap analysis for Mediterranean coastal fishes and determine the representation of three key biodiversity components in current MPAs: taxonomic diversity, phylogenetic diversity and functional diversity. We test the effectiveness of current MPA locations at representing these biodiversity components at the regional scale using a null model obtained by randomizing the placement of current MPAs across the continental shelf. Specifically, we address the following questions:

1. Does the current Mediterranean system achieve a good representation of coastal fish species? We assess the representation of coastal fish species within protected areas by quantifying the achievement of species-specific representation targets set to be inversely proportional to species' range sizes (Rodrigues et al., 2004a; Venter et al., 2014).

2. Is species representation related to phylogenetic and functional distinctiveness? Ideally, protected area systems should be large enough to achieve an effective representation of all species. However, practically, full representativeness is rarely achieved for all species, as is the case for the Mediterranean where the coverage of current MPAs is only $2.3 \%$ of the continental shelf. Within the general context of scarce resources for biodiversity conservation, prioritizing conservation efforts towards the most distinct or unique species seems essential (Vane Wright et al., 1991; Isaac et al., 2007; Bottrill et al., 2008). Thus, a positive bias in the representation of the most phylogenetically and functionally distinct species would be a valuable property for the current Mediterranean system of MPAs. This is because the protection of species carrying the largest amount of unique evolutionary history would result in greatest amount of phylogenetic diversity protected than the inclusion of young species with many close relatives (Nee \& May 1997). In the same vein, if the species that support the most distinct combinations of traits are not adequately protected, some particular functions might be highly vulnerable, potentially imperilling particular ecosystem processes (Díaz et al., 2006). 
3. What is the overall conservation effectiveness of the Mediterranean MPA system for taxonomic, phylogenetic and functional diversity? Recent studies have promoted (Cadotte \& Davies, 2010) or demonstrated (Pio et al., 2011) the utility of phylogenetic measures incorporating information about species range sizes or abundances for conservation planning and have called for an examination of how existing reserve networks protect these multiple aspects of biodiversity (Tucker et al., 2012). Here, we evaluate the overall conservation effectiveness (CE) of the Mediterranean MPA system at representing taxonomic, phylogenetic and functional fish diversity at the regional scale using metrics that integrate species phylogenetic and functional relationships along with target achievement. To investigate potential surrogates between diversity components for conservation planning, we examine the pairwise correlations between the CE metrics for both the current MPA system and systems of randomly located MPAs.

\section{METHODS}

\section{Data}

\section{Species data}

We obtained species distributions data for the 340 coastal Mediterranean fishes from a regional geographic range database compiled at the University of Montpellier 2 (Ben Rais Lasram et al., 2009; Coll et al., 2010; Mouillot et al., 2011; Albouy et al., 2012, 2013). For more details, see Table S1 and Appendix S1.

\section{MPA data}

We compiled data on existing national and international MPAs in the Mediterranean Sea (MedPAN personal communication, http://www.medpan.org). We excluded from the analysis those sites that (1) had not yet been formally declared as MPAs (e.g. proposed but not yet classified) or (2) are not directly dedicated to the protection of fish species (e.g. the Pelagos sanctuary dedicated to the protection of marine mammals). A total of 99 coastal MPAs located in 18 countries were identified (Fig. 1, see Table S2 in Supporting Information for a complete list of MPAs used herein).

\section{Phylogenetic and Functional data}

We used a previously published phylogeny of Mediterranean teleost species (Meynard et al., 2012). Non-coastal species were pruned to obtain a final phylogeny summarizing the evolutionary relationships among 265 of the 340 coastal fish species selected in this study. See Appendix S1 and Meynard et al. (2012) for details.

For the 265 species included in the phylogeny, we compiled information on nine habitat characteristics and life history traits (see Appendix S1 for a complete description of the traits and their modalities). We calculated pairwise functional distances between species using the Gower distance (Gower \& Legendre, 1986; Legendre \& Legendre, 1998). We then built a dendrogram depicting the functional relationships among species, hereafter referred to as the 'functional tree' (Petchey \& Gaston, 2002). See Appendix S1 for details.

\section{Assessing the representation of coastal fish species: gap analysis}

Gap analysis is a procedure for assessing the extent to which native species are protected by existing conservation area networks (Jennings, 2000; Rodrigues et al., 2004a,b; Araújo et al., 2007). The first step in a gap analysis is the setting of species-specific representation targets (Soulé \& Sanjayan,

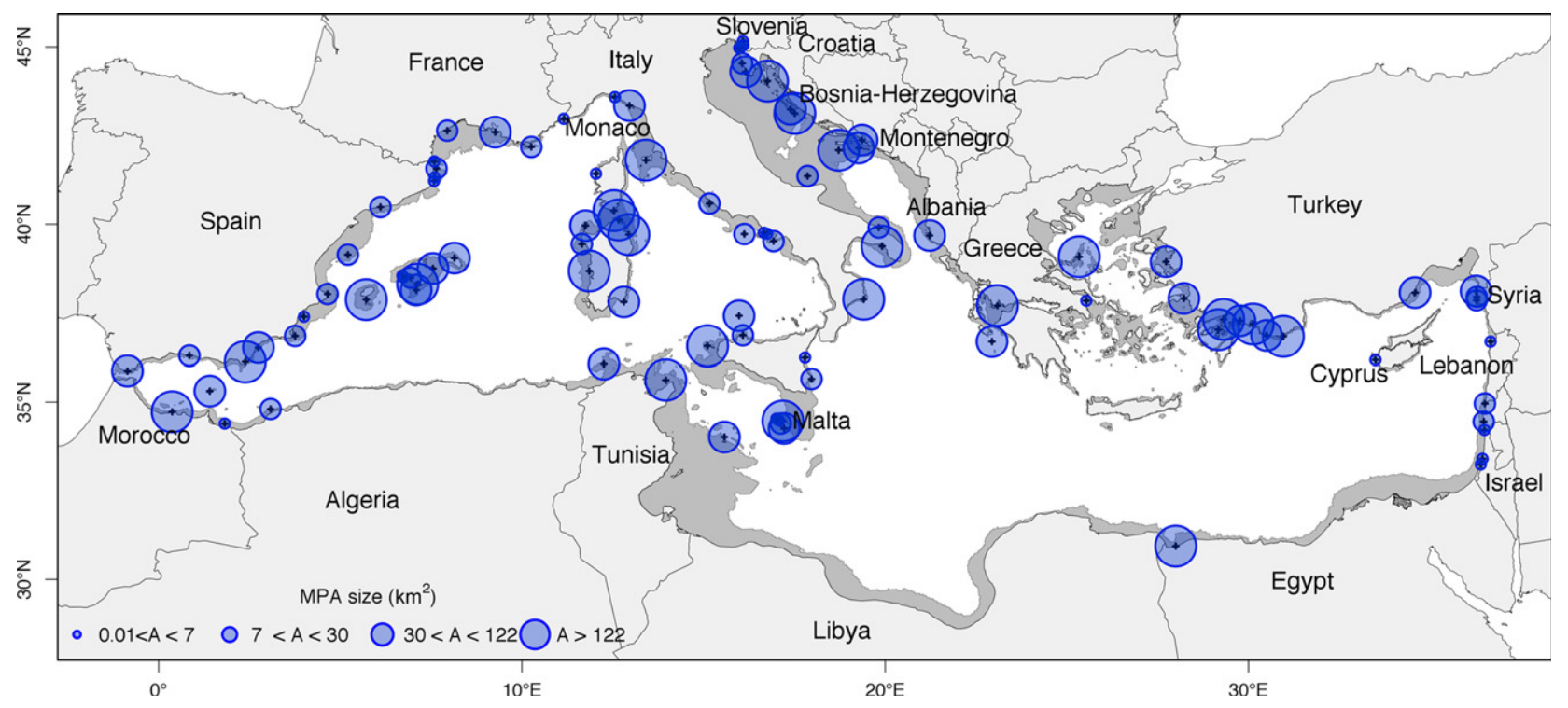

Figure 1 Map of the Mediterranean Sea highlighting the continental shelf in grey and the locations of the 99 marine-protected areas (MPAs) considered in the study (blue circles with size proportional to MPA size). 
1998). Ideally, conservation targets should relate directly to the probability of species persistence (Araújo \& Williams 2000). However, these kinds of data are usually unavailable or incomplete, and validations of persistence predictions are extremely difficult to undertake (Araújo et al., 2002). An indirect approach is to set different targets for species with different range sizes, such that species with restricted ranges have more ambitious targets. The rationale is that restrictedrange species tend to present lower local abundance and higher demographic stochasticity, thus higher extinction risk (Gaston, 2003; Harnik et al., 2012). Accordingly, a representation target of $100 \%$ is usually set for species with restricted ranges, and a target of $10 \%$ is used for widespread species (Larsen et al., 2011). For species with intermediate range sizes, the target is interpolated as a linear function of log-transformed area of occupancy (Rodrigues et al., 2004a; Tognelli et al., 2008; Venter et al., 2014). An additional approach is to modify area-based targets on the basis of information about species level of threat based on the IUCN Red List categories (Williams et al., 2005; Hannah et al., 2007; Kark et al., 2009). As no consensus exists regarding the area of occupancy (AOO) boundaries for the definition of restricted-range and widespread species (100\% and 10\% representation target boundaries), and because it has been shown that target definition has a major impact on the results of gap analyses (Araújo, 1999; Kujala et al., 2011; Vimal et al., 2011), we refrained from using one representation target alone. Instead, we selected four species-specific representation targets linearly interpolated between boundaries chosen in the distribution of fish AOOs (targets A, B, C and $\mathrm{D}$, Table 1). We additionally modified these four sets of targets to account for information about levels of threats to species based on the IUCN Red List categories [targets $\mathrm{A}(\mathrm{IUCN}), \mathrm{B}(\mathrm{IUCN}), \mathrm{C}(\mathrm{IUCN})$ and $\mathrm{D}(\mathrm{IUCN})$, Table 1]. A complete description of the strategy used to define targets is given in Appendix S1.

Table 1 Area-based species-specific conservation targets used for the gap analysis.

\begin{tabular}{lcll}
\hline Target name & Lower boundary & Upper boundary & IUCN \\
\hline $\mathrm{A}$ & 1000 & 148503.4 & No \\
$\mathrm{B}$ & 1000 & 213582.7 & No \\
$\mathrm{C}$ & 25543.9 & 148503.4 & No \\
$\mathrm{D}$ & 25543.9 & 213582.7 & No \\
$\mathrm{A}_{\text {IUCN }}$ & 1000 & 148503.4 & Yes \\
$\mathrm{B}_{\mathrm{IUCN}}$ & 1000 & 213582.7 & Yes \\
$\mathrm{C}_{\mathrm{IUCN}}$ & 25543.9 & 148503.4 & Yes \\
$\mathrm{D}_{\text {IUCN }}$ & 25543.9 & 213582.7 & Yes \\
\hline
\end{tabular}

For each set of targets, the AOO boundaries $\left(\mathrm{km}^{2}\right)$ for the definition of restricted-range (lower boundary) and widespread species (upper boundary; $100 \%$ and $10 \%$ representation target boundaries, see Methods) are given along with the information about inclusion of IUCN information.

\section{Phylogenetic and functional distinctiveness analyses}

We measured evolutionary distinctiveness at the species level using the evolutionary distinctiveness index (ED; Isaac et al., 2007) and generalized its use to also measure functional distinctiveness. This index evaluates the distinctiveness of a particular species $s$ with respect to the regional phylogenetic (or functional) tree using the following formula:

$$
\mathrm{ED}_{s}=\sum_{b \in\{T, s\}} \frac{\lambda_{b}}{S_{b}},
$$

where $b \in\{T, s\}$ are the branches belonging to the tree $T$ representing the phylogenetic (functional) relationships between all the species of the tree containing species $s . \lambda_{b}$ is the branch (edge) length, and $S_{b}$ is the number of species descendant from that branch. Individual $\mathrm{ED}_{s}$ values sum up to the total regional phylogenetic or functional diversity as measured respectively by the phylogenetic diversity (PD) index (Faith, 1992) or the functional diversity (FD) index (Petchey \& Gaston, 2002).

To look for trends towards the better protection of more distinctive species in the MPA system, we investigated the correlations (Spearman correlations) between fish functional and evolutionary distinctiveness and their target achievement.

\section{Overall assessment of taxonomic, phylogenetic and functional diversity coverage}

We evaluated the overall taxonomic diversity encompassed in MPA systems by averaging species target achievement ('taxonomic conservation effectiveness', $\mathrm{CE}_{\text {tax }}$ ):

$$
\mathrm{CE}_{\mathrm{tax}}=\frac{\sum_{s=1}^{S} P_{s}}{S},
$$

where $P_{s}$ is the proportion of the conservation target accomplished for species $S$ (if the proportion is higher than 1 , it is constrained to 1 ), and $S$ is the total number of species.

To evaluate the effectiveness with which MPAs protect overall phylogenetic and functional diversity, we developed a new measure of 'conservation effectiveness' (CE index). The $\mathrm{CE}$ index is the sum of the conservation achievement of all the branches in a phylogenetic (or functional) tree, with conservation achievement for internal branches being obtained by taking the maximum among the subtending species:

$$
\mathrm{CE}=\frac{\sum_{b \in B}\left(\lambda_{b} \times \max \left(P_{s}, s \in S_{b}\right)\right)}{D_{\mathrm{tot}}},
$$

where $B$ is the set of all the branches in the tree, $\lambda_{b}$ is the length of branch $b, P_{s}$ is the proportion of the conservation target accomplished for species $s$ (in case the proportion is higher than 1 , it is constrained to 1$), S_{b}$ is the set of species descendant from branch $b$, and $D_{\text {tot }}$ is the total regional phylogenetic or functional diversity as measured respectively by 
the PD index or the FD index. CE ranges between zero, when all the species in the assemblage are absent from the protected area system, and one, when conservation targets are met for all species. By measuring conservation achievement for internal branches as the maximum among the subtending species, the index is intended to provide a conservative measure of effectiveness, considering the evolutionary history of internal branches preserved when a least one representative species achieves its representation target. For comparison, we additionally evaluated functional and phylogenetic diversity coverage using minimum-spanning measures (i.e. using the PD and FD indexes, without taking into account representation targets achievement and considering an internal branch of the regional tree as covered when at least one subtending species has any overlap with the PA system; e.g. Rodrigues et al., 2011).

\section{Evaluating MPAs against a null model of protected areas location}

Given the current Mediterranean system of MPAs (covering $2.3 \%$ of the continental shelf which is about $11843.81 \mathrm{~km}^{2}$ ), full representation of species cannot be achieved regardless of the strategy used to define targets. Therefore, we investigated the degree to which the current spatial arrangement of MPAs achieves conservation better than expected by chance by comparing the effectiveness of existing MPAs to random systems. We used an algorithm that rotates and places randomly the polygons of the existing Mediterranean MPAs on the continental shelf. It was constrained to ensure that all the MPAs overlap totally with the continental shelf and do not overlap with the coastline and other protected areas. We generated 999 random MPA systems to obtain null frequency distributions for (1) the representation target achieved for each species, (2) the correlation between target achievement and phylogenetic and functional distinctiveness, (3) PD and FD levels gathered by MPA systems as well as (4) taxonomic, phylogenetic and functional $\mathrm{CE}$ values. We estimated the empirical probabilities of obtaining values for random systems at least as extreme as the one that was actually observed in Mediterranean MPAs ( $P$ hereafter, with $P=P(X \geq o b s)$ ) by inspecting the positions of the levels currently achieved in MPAs in the corresponding null frequency distributions.

We additionally used the results of the null model analysis to investigate the relationship between the taxonomic, phylogenetic and functional CE of protected areas systems. Using major axis regression (Legendre \& Legendre, 1998) between CE values for the 999 random systems and the current MPA system, we investigated the correlation between squared regression residuals and the taxonomic, phylogenetic and functional CE values to look for any trend in the linkage of $\mathrm{CE}$ values with the increase in conservation effectiveness.

All data manipulations and analyses described above were implemented within the $\mathrm{R}$ statistical programming environment (R 3.0.2; R Core Team, 2013). Geospatial manipulations were performed under an equal area projection suitable for the Mediterranean basin (information available at http:// spatialreference.org/ref/epsg/3035/).

\section{RESULTS}

\section{Characteristics of the Mediterranean coastal fish assemblage and MPAs}

Areas of occupancy of Mediterranean coastal fishes ranged from $91.76 \mathrm{~km}^{2}$ (Didogobius schlieweni) to $484698.30 \mathrm{~km}^{2}$ (for those species extending all over the continental shelf: Carcharhinus brevipinna, Chelon labrosus, Liza ramada, Liza saliens, Mobula mobular, Mugil cephalus), with most of these being small relative to the area of the continental shelf, as shown by the median AOO $\left(79417.62 \mathrm{~km}^{2}\right)$ which corresponded to $15.41 \%$ of the continental shelf area. The distribution of AOO was negatively skewed $(\mathrm{g} 1=1.10)$ and leptokurtic $(\mathrm{g} 2=0.21)$ with the most populated class (127 species) being also the smallest $\left(0-50,000 \mathrm{~km}^{2}\right)$, in agreement with most published range size distributions (Gaston, 1998; Fig. S1). Species range sizes were negatively correlated with the latitude of their centroid (Spearman's $\rho$ : $-0.36, P<0.001$ ).

The sizes of Mediterranean MPAs ranged from $0.16 \mathrm{~km}^{2}$ (marine natural monument Cape Madona, Slovenia) to $2179.88 \mathrm{~km}^{2}$ (Alonissos-Vories Sporades National Marine Park, Greece), and the system consisted mainly of small MPAs as exhibited by their strongly negatively skewed size distribution $\quad\left(\right.$ mean $=119.63 \mathrm{~km}^{2}, \quad$ median $=30.3 \mathrm{~km}^{2}$, g1 = 5.26). The density of MPAs was higher on the northern coast of the Mediterranean Sea than on the southern coast with only 8 among 99 located on the North African continental shelf (Fig. 1).

\section{Species representation in MPAs}

We identified 16 total-gap species (i.e. whose ranges do not overlap with any MPA) of the 340 coastal species (Table S1). Among these 16 species, the common sawfish (Pristis pristis) is classified as 'critically endangered' according to the IUCN Red List and likely extincts over its Mediterranean range, while all of the other 15 species are either 'data deficient', 'least concern' or 'not listed' according to the IUCN Red List (Table S1). The AOO of total-gap species varied greatly (mean: $1503.95 \mathrm{~km}^{2}$, SD: 2227.37) but were all small with respect to the regional assemblage. All the other species (i.e. 324) only partially achieved their representation target, which was true regardless of the strategy used to define targets. The percentage of target accomplishment never exceeded 35.38\% (Fig. 2, Table S1).

Current MPAs at the Mediterranean continental shelf yield fewer total-gap species than expected by chance $(P=0.003$, Fig. S2). For all the eight set of targets, 110 species $(32.35 \%$ of 340 species) achieved a significantly higher proportion of their representation target in random systems than in the current MPA system ( $P>0.975$, Fig. 3). Conversely, 91 species $(26.76 \%)$ achieved a significantly higher proportion of their representation target in the current MPA system $(P<0.025$, Fig. 3). 


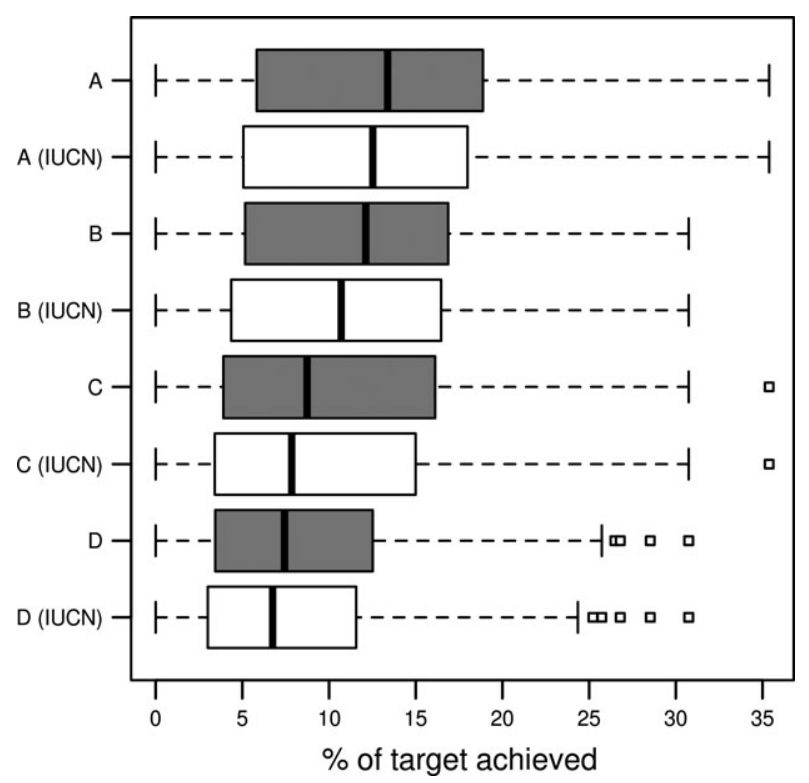

Figure 2 Percentages of conservation target achievement for the 340 coastal fish species considered in the study.

Distributions of target achievement are given for the eight set of area-based species-specific targets used in the analyses. See Table 1 for targets definition.

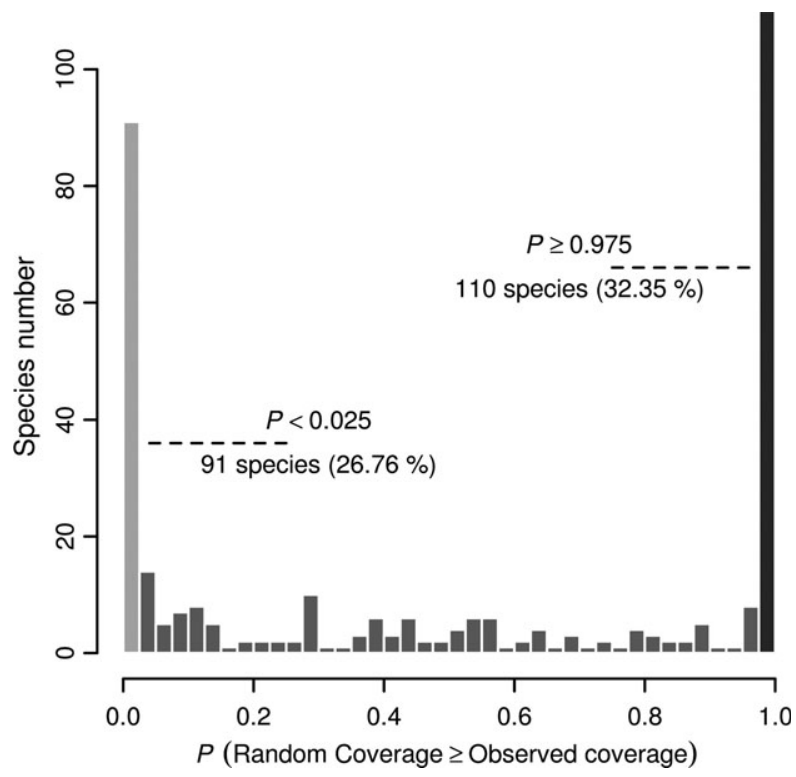

Figure 3 Frequency distribution of the probabilities that species $(n=340)$ target achievement is higher or equal in systems of randomly sited marine-protected areas (MPAs) than in the current Mediterranean MPA system.

\section{Phylogenetic and functional diversity analyses}

\section{Target achievement and distinctiveness}

Fish target achievement and evolutionary distinctiveness were significantly and negatively correlated $(\rho=-0.13, P=0.03$; Fig. 4), while the correlation was weaker and non-significant between target achievement and functional distinctiveness ( $\rho=0.09, P=0.14$; Fig. 4 ). These correlations were both significantly lower $(P>0.999$; Fig. 4$)$ than correlations obtained for random MPA systems, whatever the set of targets under consideration (Fig. S3). Species functional and evolutionary distinctiveness were negatively but nonsignificantly correlated $(\rho=-0.06, P=0.30)$.

\section{Conservation effectiveness}

The current Mediterranean marine-protected areas provided low $\mathrm{CE}$ values for taxonomic, phylogenetic and functional diversity components whatever the target scheme (Fig. 5, Fig. S4). For all three diversities, we found contrasting results with regard to null expectations depending on the level of demand for protection arising from the specified targets (i.e. the species' AOO used to define restricted-range species, see Table 1). For taxonomic diversity, the CE values did not differ from that expected by chance for the more demanding targets (C, $\mathrm{C}_{\mathrm{IUCN}}, \mathrm{D}$ and $\mathrm{D}_{\mathrm{IUCN}}$ ) but were marginally significantly higher than expected by chance for the less demanding targets (A, $A_{I U C N}, B$ and $B_{I U C N}$; Fig. 5, Fig. S4). For the phylogenetic and functional components, the $\mathrm{CE}$ levels were significantly lower than expected by chance only when increasing the species' AOO used to define restricted-range species (targets C, $\mathrm{C}_{\text {IUCN }}, \mathrm{D}$ and $\left.\mathrm{D}_{\text {IUCN }}\right)$. The scattering of the residuals of major axis regression between taxonomic and phylogenetic CE did not show any trend with the increase in both $\mathrm{CE}$ values (Table S3.A); however, the residuals of major axis regression between taxonomic and functional CE values increased significantly with both CE values (Table S3.B), indicating a negative trend in the correlation between CEs with increasing effectiveness for either taxonomic and functional diversity. The scattering of the residuals of major axis regression between phylogenetic and functional CE was positively and significantly correlated with both CE values (Table S3.C), indicating a negative trend in the similarity between CEs with increasing effectiveness for either phylogenetic or functional diversity.

When not considering target achievement and using the $\mathrm{PD}$ and FD indexes to evaluate the coverage of phylogenetic and functional diversity (considering a species as covered when it has any overlap with the PA system), the current Mediterranean MPA system yielded significantly higher representation levels than random systems (Fig. S5).

\section{DISCUSSION}

We provide the first comprehensive analysis of the effectiveness of Mediterranean marine-protected areas (MPAs) to represent coastal fish taxonomic, phylogenetic and functional diversities. Recent investigations based on hotspot analyses have highlighted a good congruence between Mediterranean MPAs and areas of high taxonomic diversity but substantial mismatches between MPAs and areas of simultaneously high biodiversity and high cumulative threats (Mouillot et al., 2011; Coll et al., 2012). The present work based on 


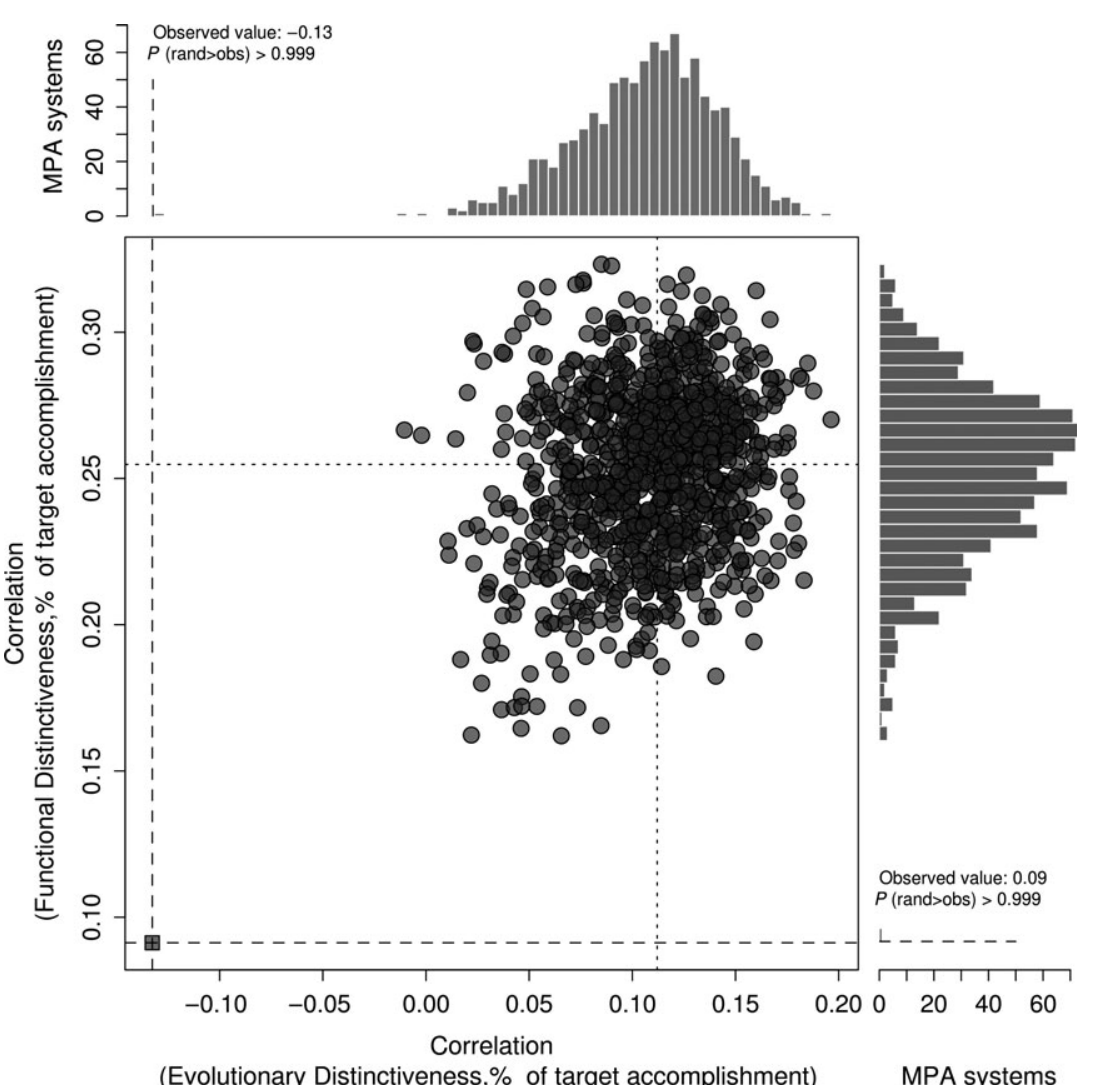

Figure 4 Relationships (Spearman's rho) between species target achievement and their phylogenetic ( $x$-axis) and functional ( $y$-axis) distinctiveness for the 999 random systems (circles) and the current Mediterranean marine-protected area (MPA) system (square). Grey histograms on the edges represent the frequency distribution of Spearman's rho across the random systems. Dashed lines indicate the values for the current MPA system. Doted lines indicate median values for each variable. Results are given for target A (see Table 1), and results for other set of targets are equivalent and presented in Fig. S3.

species-specific representation targets, and a null model analysis challenges previous results about the efficiency of the current MPA system in representing coastal fish species and highlights ongoing challenges for the simultaneous representation of different components of the Mediterranean fish biodiversity.

\section{Does the current Mediterranean system achieve a good representation of coastal fish species?}

We find that, while they include a least one occurrence of most species, the Mediterranean MPAs fail to achieve any of the species-specific representation targets explored herein. Regardless of the strategy used to define targets, none of the Mediterranean coastal fish species examined achieved more than $36 \%$ of their target (Fig. 2). Previous studies have found that alternative representation targets can lead to different results in gap analyses (Araújo, 1999; Kujala et al., 2011; Vimal et al., 2011). Yet, our study shows that the proportion of the Mediterranean continental shelf currently under protection is so small (c. 2.5\%) that even the less demanding targets are achieved only partially (Fig. 2). Among the 16 species that did not overlap with any protected area, six are endemic to the Mediterranean Sea: five goby species, the De Buen's goby (Buenia affinis), the Liechtenstein's goby (Corcyrogobius liechtensteini), Didogobius splechtnai, the Kern's goby (Pomatoschistus knerii) and the large-scaled goby (Thorogobius macrolepis), and one mud eel species (Panturichthys fowleri; Ben Rais Lasram et al., 2010). Recent investigations show that among these species, four (Buenia affinis, Corcyrogobius liechtensteini, Didogobius splechtnai and Thorogobius macrolepis) might lose their thermal-realized niche across the Mediterranean continental shelf in the 21st century (Albouy et al., 2013). The total-gap species have relatively small ranges, their majority (11 species) is not yet accounted for by the IUCN Red List framework (either data deficient or not evaluated), and one of them (the common sawfish, Pristis pristis) is evaluated as critically endangered and may no longer occur over its Mediterranean range. The conservation of such small-ranged, poorly known and already, or predicted to be, highly threatened species may represent concerns for the establishment of future Mediterranean MPAs. Such small-ranged species may constrain the most used spatial prioritization algorithms seeking to maximize species representation (e.g. Zonation, Moilanen et al., 2012; Marxan, Ball et al., 2009), and the implications of constraining conservation solutions towards species with such uncertain fates must be evaluated carefully. 

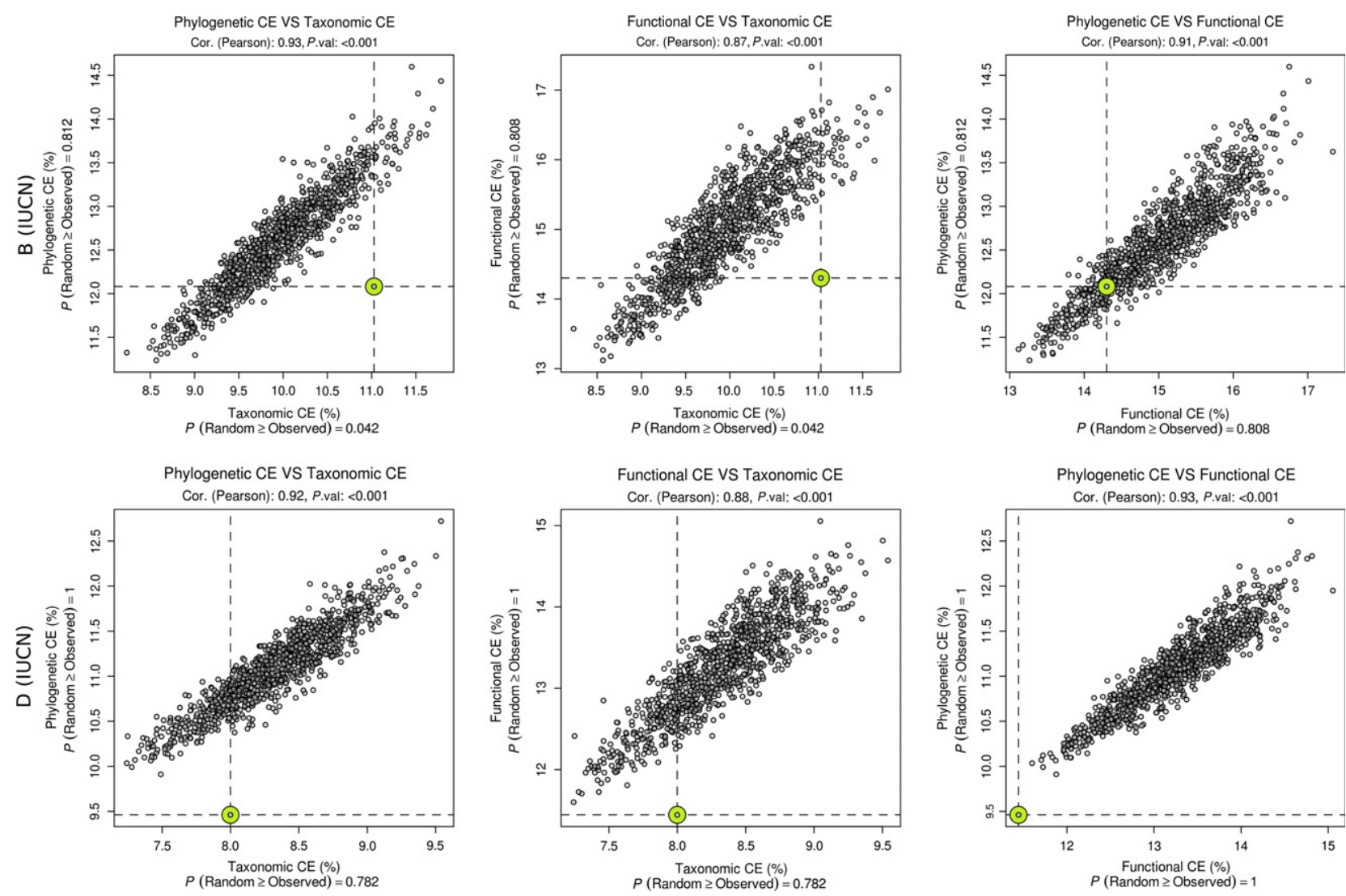

Figure 5 Distributions of the values of the taxonomic, functional and phylogenetic conservation effectiveness (CE) index for the 999 random systems (grey circles) and the current Mediterranean marine-protected area (MPA) system (large green circle) and their relationships. Dashed lines indicate the values for the current MPA system. Results are given for targets B and D including IUCN threat levels (see Table 1), and results for the remaining set of targets are given in Fig. S4.

A positive finding is that the current system of MPAs does better than random at representing species at least once somewhere in the system (Fig. S2). This result is probably a consequence of the high concentration of restricted-range species in the northern Mediterranean coast, which is congruent with the greater density of MPAs in the northern Mediterranean (Fig. 1); that is small-ranged species in the northern part of the Mediterranean Sea benefited from the northward bias in MPAs location. Nevertheless, when the achievement of species-specific conservation targets is considered, our results confirm the difficulty for national (or even subnational) conservation initiatives in achieving their goal when evaluated in a regional context (Kark et al., 2009). Indeed, our analyses showed that the current MPA system provides significantly higher target achievement from that expected by chance for only $26.76 \%$ of the species and significantly lower representation levels for $32.35 \%$ of the species (Fig. 3). These results were contrasting. They imply that for $73.24 \%$ of the species, an equivalent or better representation could have been achieved without geographical constraints on the positioning of protected areas. However, a substantial number of species (91) achieved a better protection in current MPAs than in random systems (Fig. 3). Among these species, 30 are endemic to the Mediterranean, whereas only
13 among the 110 species achieving better representation in random systems are endemic to the region. These results indicate that the current Mediterranean MPA system represents a valuable starting point for further extension. However, they highlight that coordination of conservation efforts at the regional scale is now required to achieve an optimal biodiversity conservation in the Mediterranean (Kark et al., 2009; Mazor et al., 2013).

\section{Is there a relationship between species representation and their phylogenetic and functional distinctiveness?}

Investigating the relationship between species' functional distinctiveness and target achievement revealed a lack of tendency towards a better protection of the most functionally distinctive species (Fig. 4, Fig. S3). This implies that beyond a non-effective coverage of all Mediterranean coastal fish, the representation of the most functionally unique species is not promoted by the current location of MPAs, overlooking the potential contribution of rare combinations of life history traits to the maintenance of ecosystem functioning (Díaz et al., 2006). Evolutionary distinctiveness was negatively correlated with target achievement (Fig. 4, Fig. S3) revealing a 
tendency to better represent the less distinct species such that the current system of MPAs is biased towards the representation of redundant phylogenetic information. In current MPAs, the correlations between target achievement and both phylogenetic and functional distinctiveness were lower than expected by chance, and this was regardless of the scheme used for targets (Fig. 4, Fig. S3). This result suggests that the geopolitical constraints that have led to the current spatial distribution of MPAs around the Mediterranean basin have prevented the system from focusing on the most distinctive fish species. Further, because phylogenetic and functional distinctiveness are uncorrelated for Mediterranean fishes, our analysis suggests that particular biodiversity components may not be effective surrogates for other components when establishing conservation strategies. Investigating further the results of the null model analysis revealed that the correlations between target achievement and species distinctiveness are independent between the phylogenetic and functional components (Fig. 4). Nevertheless, some random systems provided among the highest positive correlations between target achievement and species distinctiveness for both the phylogenetic and the functional components (Fig. 4). This suggests that in a context of scare resources for conservation, solutions maximizing the joint conservation of multiple biodiversity components may exist and should be favoured when establishing or extending PA systems.

\section{What is the overall conservation effectiveness of the MPA system for taxonomic, phylogenetic and functional diversity?}

The conservation effectiveness of the current Mediterranean MPA system is low for taxonomic, phylogenetic and functional diversities (between $8 \%$ and $17 \%$, depending on the diversity component and the set of conservation target, Fig. 5). The investigation of the degree to which the current spatial arrangement of MPAs achieves conservation better than expected by chance yielded contrasting results when increasing the species' AOO used to define restricted-range species (from 1000 to $25543.9 \mathrm{~km}^{2}$, corresponding to the first quartile in the distribution of AOOs; Fig. 5, Fig. S4). Taxonomic conservation effectiveness was marginally higher than expected from random placement of MPAs in the case of the less demanding targets (targets $A$ and $B ; 0.042<P<0.049$; Fig. 5, Fig. S4). This result is again congruent with the greater density of both MPAs and small-ranged species in the northern Mediterranean (Fig. 1). However, the functional and phylogenetic conservation effectiveness of the Mediterranean system of MPAs was markedly lower than in random MPA systems under all target schemes, being significantly lower than expected in the case of the more demanding targets (targets $C$ and D; $P>0.989$; Fig. 5, Fig. S4). Thus, considering taxonomic diversity as a surrogate for all biodiversity components when evaluating conservation effectiveness may not be appropriate.
We detected high correlation levels between the conservation effectiveness of the three diversity components in random MPA systems, suggesting at first glance high levels of surrogacy in conservation effectiveness (Fig. 5, Fig. S4). However, these high correlations were detected over the very constrained range of conservation effectiveness achieved by random MPA systems, reaching a maximum of $20 \%$ for functional diversity under target scheme A (Fig. 5, Fig. S4). Further, when we evaluated trends in the linkage of CE values with the increase in conservation effectiveness, we found that whenever conservation effectiveness increased for the functional component, so did the discrepancies with the taxonomic and phylogenetic components (Table S3). These results need to be interpreted cautiously given the small range of effectiveness that the size of the Mediterranean MPA system implied in this study, and such trends need to be studied more rigorously using simulations modulating the size of protected area systems. Nevertheless, they suggest potential to develop conservation approaches with limited resources that would involve the implementation of consensus solutions, involving the development of multicriteria conservation planning methods accounting for complementarity in the representation of ecological functions and evolutionary history.

When evaluating functional and phylogenetic diversity coverage using the minimum-spanning measures (PD, FD), the current system of MPA provided high levels of $\mathrm{CE}$ (93.7\% and $99.48 \%$ of the regional phylogenetic and functional diversity covered, respectively) that were significantly higher than expected by chance (Fig. S5). Although this latter result is implicit given the low, and significantly lower than random, number of total-gap species in current MPAs (Fig. S2), it has some implications. It has been argued (building on high covariation between $\mathrm{PD}$ and taxonomic richness at large scales) that the use of phylogenetic information may be superfluous for conservation planning (Rodrigues et al., 2011). Our analysis yielded dramatically lower conservation effectiveness outcomes when considering species conservation targets in the evaluation of functional and phylogenetic diversity coverage than when using the PD or the FD index (Fig. S5). This confirms that measures incorporating information about species ranges, abundances or, as we have done here, species-specific target achievement add value to our understanding of how biodiversity components may be accounted for by conservation planning (Cadotte \& Davies, 2010; Pio et al., 2011; Tucker et al., 2012).

The critical conservation status of the different components of Mediterranean coastal fish biodiversity highlighted here, as well as their spatial mismatches (Mouillot et al., 2011), demonstrates that integrative conservation approaches connecting biogeography, evolutionary and functional ecology may be required if we want to achieve protected area networks representative of all biodiversity components. Further, our results show that the establishment of transnational conservation strategies would be of great benefit for biodiversity. Such transnational 
conservation strategies have recently been shown to have a great potential to reduce dramatically the cost of threatened species conservation in the Mediterranean Sea (Mazor et al., 2013). Building on multicomponents conservation approaches like here, in a transnational context, may represent the best solution to mitigate the current threats to Mediterranean biodiversity.

\section{ACKNOWLEDGEMENTS}

F.G. and M.B.A. were supported by the 'Range Shift' project (PTDC/AAC-AMB/098163/2008) from Fundação para a Ciência e a Tecnologia (Portugal), cofinanced by the European Social Fund. The 'Rui Nabeiro' Biodiversity Chair is financed by Delta Cafés. C.A. was supported by a MELSFQRNT post-doctoral fellowship. J.C. acknowledges the biodivERsA BUFFER project and the EU-FP7 COCONET project for financial support. M.B.A. also acknowledges the Integrated Program of IC\&DT Call No. 1/SAESCTN/ALENT07-0224-FEDER-001755, the Spanish Research Council (CSIC) and the Danish NSF for support of his research. D.M. was supported by a Marie Curie International Outgoing Fellowship (FISHECO) with agreement number IOFGA-2009-236316. This work was partly funded by the Total Foundation, the 'Fondation pour la Recherche sur la Biodiversité' (project BIODIVMED).

\section{REFERENCES}

Abdulla, A., Gomei, M., Hyrenbach, D., Notarbartolo-diSciara, G. \& Agardy, T. (2009) Challenges facing a network of representative marine protected areas in the Mediterranean: prioritizing the protection of underrepresented habitats. ICES Journal of Marine Science, 66, 22-28.

Albouy, C., Guilhaumon, F., Araújo, M.B., Mouillot, D. \& Leprieur, F. (2012) Combining projected changes in species richness and composition reveals climate change impacts on coastal Mediterranean fish assemblages. Global Change Biology, 18, 2995-3003.

Albouy, C., Guilhaumon, F., Leprieur, F., Ben Rais Lasram, F., Somot, S., Aznar, R., Velez, L., Le Loc'h, F. \& Mouillot, D. (2013) Projected climate change and biogeography of coastal Mediterranean fishes. Journal of Biogeography, 40, 534-547.

Alós, J. \& Arlinghaus, R. (2013) Impacts of partial marine protected areas on coastal fish communities exploited by recreational angling. Fisheries Research, 137, 88-96.

Araújo, M.B. (1999) Distribution patterns of biodiversity and the design of a representative reserve network in Portugal. Diversity and Distributions, 5, 151-163.

Araújo, M.B. \& Williams, P.H. (2000) Selecting areas for species persistence using occurrence data. Biological Conservation, 96, 331-345.

Araújo, M.B., Williams, P.H. \& Turner, A. (2002) A sequential approach to minimise threats within selected conservation areas. Biodiversity and Conservation, 11, 1011-1024.
Araújo, M.B., Lobo, J.M. \& Moreno, J.C. (2007) The effectiveness of Iberian protected areas for conserving terrestrial biodiversity. Conservation Biology, 21, 1423-1432.

Ball, I.R., Possingham, H.P. \& Watts, M. (2009) Marxan and relatives: software for spatial conservation prioritization. Spatial conservation prioritization: quantitative methods and computational tools (ed. by A. Moilanen, K.A. Wilson and H.P. Possingham), pp. 185-195. Oxford University Press, Oxford.

Ben Rais Lasram, F., Guilhaumon, F. \& Mouillot, D. (2009) Fish diversity patterns in the Mediterranean Sea: deviations from a mid-domain model. Marine Ecology Progress Series, 376, 253-267.

Ben Rais Lasram, F., Guilhaumon, F., Albouy, C., Somot, S., Thuiller, W. \& Mouillot, D. (2010) The Mediterranean Sea as a 'cul-de-sac' for endemic fishes facing climate change. Global Change Biology, 16, 3233-3245.

Bianchi, C.N. \& Morri, C. (2000) Marine biodiversity of the Mediterranean Sea: situation, problems and prospects for future research. Marine Pollution Bulletin, 40, 367-376.

Bottrill, M.C., Joseph, L.N., Carwardine, J., Bode, M., Cook, C., Game, E.T., Grantham, H., Kark, S., Linke, S., McDonald-Madden, E., Pressey, R.L., Walker, S., Wilson, K.A. \& Possingham, H.P. (2008) Is conservation triage just smart decision making? Trends in Ecology \& Evolution, 23, 649654.

Cadotte, M.W. \& Davies, T.J. (2010) Rarest of the rare: advances in combining evolutionary distinctiveness and scarcity to inform conservation at biogeographical scales. Diversity and Distributions, 16, 376-385.

Cadotte, M.W., Cavender-Bares, J., Tilman, D. \& Oakley, T.H. (2009) Using Phylogenetic, Functional and Trait Diversity to Understand Patterns of Plant Community Productivity. PLoS One, 4, e5695.

Claudet, J. \& Fraschetti, S. (2010) Human-driven impacts on marine habitats: a regional meta-analysis in the Mediterranean Sea. Biological Conservation, 143, 2195-2206.

Claudet, J., Antonio Garcia-Charton, J. \& Lenfant, P. (2011) Combined effects of levels of protection and environmental variables at different spatial resolutions on fish assemblages in a marine protected area. Conservation Biology, 25, 105114 .

Clemente, S., Hernandez, J.C., Rodriguez, A. \& Brito, A. (2010) Identifying keystone predators and the importance of preserving functional diversity in sublittoral rocky-bottom areas. Marine Ecology Progress Series, 413, 55-67.

Coll, M., Piroddi, C., Steenbeek, J. et al. (2010) The biodiversity of the Mediterranean Sea: estimates, patterns, and threats. PLoS One, 5, e11842.

Coll, M., Piroddi, C., Albouy, C., Ben Rais Lasram, F., Cheung, W.W.L., Christensen, V., Karpouzi, V.S., Guilhaumon, F., Mouillot, D., Paleczny, M., Palomares, M.L., Steenbeek, J., Trujillo, P., Watson, R. \& Pauly, D. (2012) The Mediterranean Sea under siege: spatial overlap between marine biodiversity, cumulative threats and marine reserves. Global Ecology and Biogeography, 21, 465-480. 
Costello, M.J., Coll, M., Danovaro, R., Halpin, P., Ojaveer, H. \& Miloslavich, P. (2010) A census of marine biodiversity knowledge, resources, and future challenges. PLoS One, 5, e12110.

Díaz, S., Fargione, J., Chapin, F.S. \& Tilman, D. (2006) Biodiversity loss threatens human well-being. PLoS Biology, 4, e277.

Faith, D.P. (1992) Conservation evaluation and phylogenetic diversity. Biological Conservation, 61, 1-10.

Faith, D.P., Magallon, S., Hendry, A.P., Conti, E., Yahara, T. \& Donoghue, M.J. (2010) Evosystem services: an evolutionary perspective on the links between biodiversity and human well-being. Current Opinion in Environmental Sustainability, 2, 66-74.

Forest, F., Grenyer, R., Rouget, M., Davies, T.J., Cowling, R.M., Faith, D.P., Balmford, A., Manning, J.C., Proches, S., van der Bank, M., Reeves, G., Hedderson, T.A.J. \& Savolainen, V. (2007) Preserving the evolutionary potential of floras in biodiversity hotspots. Nature, 445, 757-760.

Gaston, K.J. (1998) Species-range size distributions: products of speciation, extinction and transformation. Philosophical Transactions of the Royal Society B: Biological Sciences, 353, 219-230.

Gaston, K.J. (2003) Ecology - the how and why of biodiversity. Nature, 421, 900-901.

Gaston, K.J., Pressey, R.L. \& Margules, C.R. (2002) Persistence and vulnerability: retaining biodiversity in the landscape and in protected areas. Journal of Biosciences, 27, 361-384.

Gower, J.C. \& Legendre, P. (1986) Metric and Euclidean properties of dissimilarities coefficients. Journal of Classification, 3, 5-48.

Guidetti, P., Fanelli, G., Fraschetti, S., Terlizzi, A. \& Boero, F. (2002) Coastal fish indicate human-induced changes in the Mediterranean littoral. Marine Environmental Research, 53, 77-94.

Guidetti, P., Milazzo, M., Bussotti, S., Molinari, A., Murenu, M., Pais, A., Spano, N., Balzano, R., Agardy, T., Boero, F., Carrada, G., Cattaneo-Vietti, R., Cau, A., Chemello, R., Greco, S., Manganaro, A., di Sciara, G.N., Russo, G.F. \& Tunesi, L. (2008) Italian marine reserve effectiveness: does enforcement matter? Biological Conservation, 141, 699-709.

Hannah, L., Midgley, G., Andelman, S., Araújo, M., Hughes, G., Martinez-Meyer, E., Pearson, R. \& Williams, P. (2007) Protected area needs in a changing climate. Frontiers in Ecology and the Environment, 5, 131-138.

Harnik, P.G., Simpson, C. \& Payne, J.L. (2012) Long-term differences in extinction risk among the seven forms of rarity. Proceedings of the Biological Sciences, 279, 4969-4976.

Holmlund, C.M. \& Hammer, M. (1999) Ecosystem services generated by fish populations. Ecological Economics, 29, 253-268.

Hooper, D.U., Chapin, F.S., Ewel, J.J., Hector, A., Inchausti, P., Lavorel, S., Lawton, J.H., Lodge, D.M., Loreau, M., Naeem, S., Schmid, B., Setala, H., Symstad, A.J., Vandermeer, J. \& Wardle, D.A. (2005) Effects of biodiversity on ecosystem functioning: a consensus of current knowledge. Ecological Monographs, 75, 3-35.

Humphries, C.J., Williams, P.H. \& Vanewright, R.I. (1995) Measuring Biodiversity value for conservation. Annual Review of Ecology and Systematics, 26, 93-111.

Isaac, N.J.B., Turvey, S.T., Collen, B., Waterman, C. \& Baillie, J.E.M. (2007) Mammals on the EDGE: conservation priorities based on threat and phylogeny. PLoS One, 2, e296.

Jennings, M.D. (2000) Gap analysis: concepts, methods, and recent results. Landscape Ecology, 15, 5-20.

Kark, S., Levin, N., Grantham, H.S. \& Possingham, H.P. (2009) Between-country collaboration and consideration of costs increase conservation planning efficiency in the Mediterranean Basin. Proceedings of the National Academy of Sciences USA, 106, 15368-15373.

Kujala, H., Araújo, M.B., Thuiller, W. \& Cabeza, M. (2011) Misleading results from conventional gap analysis - messages from the warming north. Biological Conservation, 144, 2450-2458.

Larsen, F.W., Londoño-Murcia, M.C. \& Turner, W.R. (2011) Global priorities for conservation of threatened species, carbon storage, and freshwater services: scope for synergy? Conservation Letters, 4, 355-363.

Legendre, P. \& Legendre, L. (1998) Numerical ecology, 2nd English edn. Elsevier Science, Amsterdam.

Mace, G.M., Gittleman, J.L. \& Purvis, A. (2003) Preserving the Tree of Life. Science, 300, 1707-1709.

Maiorano, L., Falcucci, A. \& Boitani, L. (2006) Gap analysis of terrestrial vertebrates in Italy: priorities for conservation planning in a human dominated landscape. Biological Conservation, 133, 455-473.

Margules, C.R. \& Pressey, R.L. (2000) Systematic conservation planning. Nature, 405, 243-253.

Mazor, T., Possingham, H.P. \& Kark, S. (2013) Collaboration among countries in marine conservation can achieve substantial efficiencies. Diversity and Distributions, 19, 13801393.

Meynard, C.N., Mouillot, D., Mouquet, N. \& Douzery, E.J.P. (2012) A Phylogenetic Perspective on the Evolution of Mediterranean Teleost Fishes. PLoS One, 7, e36443.

Micheli, F., Saenz-Arroyo, A., Greenley, A., Vazquez, L., Espinoza Montes, J.A., Rossetto, M. \& De Leo, G.A. (2012) Evidence That Marine Reserves Enhance Resilience to Climatic Impacts. PLoS One, 7, e40832.

Moilanen, A., Meller, L., Leppänen, J., Pouzols, F.M., Arponen, A. \& Kujala, H. (2012) Zonation - Spatial conservation planning framework and software v3.1 and user manual. Available at: http://cbig.it.helsinki.fi/software/ zonation/ (accessed 30 October 2014).

Mouillot, D., Culioli, J.M., Pelletier, D. \& Tomasini, J.A. (2008) Do we protect biological originality in protected areas? A new index and an application to the Bonifacio Strait Natural Reserve. Biological Conservation, 14, 1569-1580.

Mouillot, D., Albouy, C., Guilhaumon, F., Lasram, F.B.R., Coll, M., Devictor, V., Meynard, C.N., Pauly, D., Tomasini, 
J.A., Troussellier, M., Velez, L., Watson, R., Douzery, E.J.P. \& Mouquet, N. (2011) Protected and threatened components of fish biodiversity in the Mediterranean Sea. Current Biology, 21, 1044-1050.

Myers, R.A., Baum, J.K., Shepherd, T.D., Powers, S.P. \& Peterson, C.H. (2007) Cascading effects of the loss of apex predatory sharks from a coastal ocean. Science, 315, 18461850.

Myers, N., Mittermeier, R.A., Mittermeier, C.G., da Fonseca, G.A.B. \& Kent, J. (2000) Biodiversity hotspots for conservation priorities. Nature, 403, 853-858.

Nee, S. \& May, R. (1997) Extinction and the loss of evolutionary history. Science, 278, 692-694.

Notarbartolo-Di-Sciara, G., Agardy, T., Hyrenbach, D., Scovazzi, T. \& Van Klaveren, P. (2008) The pelagos sanctuary for Mediterranean marine mammals. Aquatic Conservation: Marine and Freshwater Ecosystems, 18, 367-391.

Petchey, O.L. \& Gaston, K.J. (2002) Functional diversity (FD), species richness and community composition. Ecology Letters, 5, 402-411.

Pio, D.V., Broennimann, O., Barraclough, T.G., Reeves, G., Rebelo, A.G., Thuiller, W., Guisan, A. \& Salamin, N. (2011) Spatial predictions of phylogenetic diversity in conservation decision making. Conservation Biology, 25, 1229-1239.

R Core Team (2013) R: a language and environment for statistical computing. R Foundation for Statistical Computing, Vienna, Austria.

Renema, W., Bellwood, D.R., Braga, J.C., Bromfield, K., Hall, R., Johnson, K.G., Lunt, P., Meyer, C.P., McMonagle, L.B., Morley, R.J., O’Dea, A., Todd, J.A., Wesselingh, F.P., Wilson, M.E.J. \& Pandolfi, J.M. (2008) Hopping hotspots: global shifts in marine Biodiversity. Science, 321, 654-657.

Roberts, C.M., Hawkins, J.P. \& Gell, F.R. (2005) The role of marine reserves in achieving sustainable fisheries. Philosophical Transactions of the Royal Society B: Biological Sciences, 360, 123-132.

Rodrigues, A.S.L., Akcakaya, H.R., Andelman, S.J. et al. (2004a) Global gap analysis: priority regions for expanding the global protected-area network. BioScience, 54, 1092-1100.

Rodrigues, A.S.L., Andelman, S.J., Bakarr, M.I. et al. (2004b) Effectiveness of the global protected area network in representing species diversity. Nature, 428, 640-643.

Rodrigues, A.S.L., Grenyer, R., Baillie, J.E.M., BinindaEmonds, O.R.P., Gittlemann, J.L., Hoffmann, M., Safi, K., Schipper, J., Stuart, N.S. \& Brooks, T.M. (2011) Complete, accurate, mammalian phylogenies aid conservation planning, but not much. Philosophical Transactions of the Royal Society B: Biological Sciences, 1579, 2652-2660.

Schindler, D.E., Carpenter, S.R., Cole, J.J., Kitchell, J.F. \& Pace, M.L. (1997) Influence of food web structure on carbon exchange between lakes and the atmosphere. Science, 277, 248-251.

Scott, J.M., Davis, F., Csuti, B., Noss, R., Butterfield, B., Groves, C., Anderson, H., Caicco, S., Derchia, F., Edwards, T.C., Ulliman, J. \& Wright, R.G. (1993) Gap analysis - a geographic approach to protection of biological diversity. Journal of Wildlife Management, 57, U673.

Scott, J.M., Murray, M., Wright, R.G., Csuti, B., Morgan, P. \& Pressey, R.L. (2001) Representation of natural vegetation in protected areas: capturing the geographic range. Biodiversity and Conservation, 10, 1297-1301.

Soulé, M.E. \& Sanjayan, M.A. (1998) Ecology - conservation targets: do they help? Science, 279, 2060-2061.

Tognelli, M.F., de Arellano, P.I.R. \& Marquet, P.A. (2008) How well do the existing and proposed reserve networks represent vertebrate species in Chile? Diversity and Distributions, 14, 148-158.

Tucker, C.M., Cadotte, M.W., Davies, T.J. \& Rebelo, T.G. (2012) Incorporating geographical and evolutionary rarity into conservation prioritization. Conservation Biology, 26, 593-601.

Vane Wright, R.I., Humphries, C.J. \& Williams, P.H. (1991) What to protect - systematics and the agony of choice. Biological Conservation, 55, 235-254.

Vanni, M.J. (2002) Nutrient cycling by animals in freshwater ecosystems. Annual Review of Ecology and Systematics, 33, 341-370.

Venter, O., Fuller, R.A., Segan, D.B., Carwardine, J., Brooks, T., Butchart, S.H.M., Di Marco, M., Iwamura, T., Joseph, L., O'Grady, D., Possingham, H.P., Rondinini, C., Smith, R.J., Venter, M. \& Watson, J.E.M. (2014) Targeting Global Protected Area Expansion for Imperiled Biodiversity. PLoS Biology, 12, e1001891.

Vimal, R., Rodrigues, A.S.L., Mathevet, R. \& Thompson, J.D. (2011) The sensitivity of gap analysis to conservation targets. Biodiversity and Conservation, 20, 531-543.

Williams, P., Hannah, L., Andelman, S., Midgley, G., Araújo, M., Hughes, G., Manne, L., Martinez-Meyer, E. \& Pearson, R. (2005) Planning for climate change: identifying minimum-dispersal corridors for the Cape proteaceae. Conservation Biology, 19, 1063-1074.

\section{SUPPORTING INFORMATION}

Additional Supporting Information may be found in the online version of this article:

Appendix S1 Supplementary methods.

Figure S1 Distribution of the areas of occupancy for the 340 Mediterranean coastal fish.

Figure S2 Distribution of total-gap species across the 999 random MPA systems and the current MPA system.

Figure S3 Distributions of the correlations between species target achievement and their phylogenetic and functional distinctiveness.

Figure S4 Distributions of the values of the functional and phylogenetic conservation effectiveness index (CE) across the 999 random MPA systems and the current MPA system and their relationships. 
Figure S5 Evaluation of functional and phylogenetic diversity coverage using minimum-spanning measure (PD, FD).

Table S1 List of species, targets and percentage of target achievement for the height set of targets.

Table S2 List of the 99 Mediterranean MPAs considered in the study and their size.

Table S3 Correlations between (1) the squared residuals of a major axis regression of functional CE values VS phylogenetic CE values for the 999 random MPA systems and the current MPA system and (2) the values of functional and phylogenetic CE values.

\section{BIOSKETCHES}

François Guilhaumon is a research scientist at IRD, Montpellier, France. His research applies theoretical and methodological advances in macroecology to conservation biology. $\mathrm{He}$ is particularly interested in understanding the distribu- tion of different aspects of terrestrial and marine diversity, at several scales, with the goal of informing regional and global conservation efforts.

Camille Albouy received his $\mathrm{PhD}$ in ecology at the University of Montpellier 2, France; he currently holds a postdoctoral researcher position at the Rimouski University. His research is focused on large-scale patterns and processes of marine fish biodiversity. He is particularly interested in forecasting the changes in marine fish biodiversity as a result of climate change.

Author contributions: F.G., C.A. and D.M. conceived the ideas; F.G., C.A., L.V. and F.B. collected the data; F.G., C.A. and L.V. analysed the data; F.G. led the writing of the manuscript with C.A., M.B.A and D.M.; all authors contributed to the final version of the manuscript.

Editor: Simon Ferrier 